\title{
The assessment of drug treatment of spastic gait
}

\author{
RN CORSTON, FRANK JOHNSON, ${ }^{*}$ RB GODWIN-AUSTEN \\ From the Department of Neurology, Derbyshire Royal Infirmary, Derby and the Department of Orthopaedics, \\ University Hospital, Nottingham*
}

SUMMARY The technique of polarised light goniometry was used to quantify objectively parameters of the spastic gait during a double-blind cross-over trial comparing the spasmolytic effects of DS103-282, baclofen and placebo. Only minimal objective and subjective changes in gait were found when the results of treatment with DS103-282 or baclofen were compared with those of treatment with placebo.

Disturbance of gait is an important disability in spinal lesions and spastic hypertonia is the only component of the disability which has proved amenable to drug treatment. Weakness is the major disability in the patient with spastic legs but increased muscle tone may contribute significantly to disability and exacerbate the weakness. ${ }^{1}$ Conversely, treatment of spasticity may be accompanied by improvement in gait. $^{2}$ This improvement is characterised by an increased rate and range of angular displacement at the knee and ankle-particularly flexion of the knee and dorsiflexion of the ankle.

Polarised light goniometry allows the measurement of angular displacements at knee and ankle during walking and thus provides an objective measurement of the changes in patterns of gait that may result from treatment. We have used the technique of polarised light goniometry to study the effect on spastic gait of the drug DS103-282, a benzothiadozole derivative with muscle relaxant properties. We have compared the results with those

Address for reprint requests: $\mathrm{Dr} \mathrm{RB}$ Godwin-Austen, General Hospital, Nottingham NG1 6HA, UK.

Received 25 March 1981 and in revised form 27 July 1981 Accepted 28 August 1981 obtained by treating patients with baclofen and with a placebo.

\section{Methods}

Ten patients were studied. Clinical details are given in table 1. All were selected from a routine neurological outpatient clinic. The criteria for selection were the presence of an abnormal gait due to lower limb spasticity which was non-progressive and which had been stable for at least two months prior to the start of the trial. Informed consent was obtained from all patients. Only three patients (numbers 4,8 , and 9) had previously received a spasmolytic agent (baclofen) and no subjective benefit had been reported at the dosage used. During the trial the dosage of baclofen tolerated was the same as had previously been used for patient number 4 but patients number 8 and 9 tolerated double the previous dosage. A doubleblind cross-over design was used. Each patient received the highest dose of drug that he could tolerate, up to a maximum of $60 \mathrm{mg}$ per day of baclofen and $24 \mathrm{mg}$ per day of DS103-282, for a two week period. A two week "wash-out" period was allowed between the administration of either drug during which time a placebo was given. The maximum tolerated dose of drug was determined during a non-blind run-in phase. Details of the doses used are given in table 1 . None of the patients was

Table 1 Clinical data of the patients studied and drug dosages used

\begin{tabular}{|c|c|c|c|c|c|}
\hline \multirow[t]{2}{*}{ Patient } & \multirow[t]{2}{*}{ Sex } & \multirow[t]{2}{*}{ Age $(y r)$} & \multirow[t]{2}{*}{ Diagnosis } & \multicolumn{2}{|c|}{ Daily dosage } \\
\hline & & & & Baclofen & DS103-282 \\
\hline 1 & $\mathbf{M}$ & 53 & Multiple sclerosis & $60 \mathrm{mg}$ & $16 \mathrm{mg}$ \\
\hline 2 & $\mathbf{M}$ & 59 & Compressive myelopathy & $60 \mathrm{mg}$ & $24 \mathrm{mg}$ \\
\hline 3 & $\mathbf{M}$ & 56 & Multiple sclerosis & $30 \mathrm{mg}$ & $24 \mathrm{mg}$ \\
\hline 4 & $\mathrm{~F}$ & 52 & Compressive myelopathy & $25 \mathrm{mg}$ & $20 \mathrm{mg}$ \\
\hline 5 & $\mathbf{F}$ & 66 & Idiopathic spastic paraparesis & $30 \mathrm{mg}$ & $20 \mathrm{mg}$ \\
\hline 6 & $\mathbf{F}$ & 71 & Compressive myelopathy & $60 \mathrm{mg}$ & $24 \mathrm{mg}$ \\
\hline 7 & $\mathrm{~F}$ & 59 & Compressive myelopathy & $30 \mathrm{mg}$ & $24 \mathrm{mg}$ \\
\hline 8 & $\mathbf{F}$ & 54 & Multiple sclerosis & $60 \mathrm{mg}$ & $24 \mathrm{mg}$ \\
\hline 9 & $\mathbf{F}$ & 50 & Multiple sclerosis & $30 \mathrm{mg}$ & $24 \mathrm{mg}$ \\
\hline 10 & $\mathrm{~F}$ & 64 & Idiopathic spastic paraparesis & $15 \mathrm{mg}$ & $24 \mathrm{mg}$ \\
\hline
\end{tabular}


receiving tricyclic antidepressants, benzodiazepines or other muscle relaxant drugs. Those patients undergoing physiotherapy continued this treatment throughout the trial.

At each visit the strength of hip flexion and knee extension was graded according to the MRC scale. General mobility was assessed and graded thus: 2-fully mobile, 1-mobile but housebound, 0-chairbound. Spasms in the lower limbs during the treatment period were graded thus: 0 -no spasm, 1-moderate, 2 - severe spasms. Urinary frequency was graded thus: 2 -severe frequency, 1 -frequency present, 0 -normal micturition. In addition the patient was asked to assess whether there had been any improvement of deterioration in the stiffness in their legs. To assess subjectively the degree to which walking was affected by spasticity the patient was asked to grade the effect of stiffness on gait as follows: 1 -interferes slightly, 2-interferes moderately, 3-interferes severely with walking. The inclinations of the foot, calf and thigh were measured using a polarised light goniometer (Crane Electronics Ltd) with three transducers. Three angles (fig 1) were recorded while the subjects walked barefoot along a level surface. Recording was achieved over the central five metres of a seven metre walkway and the patients were asked to repeat the walk until at least twelve complete swing phases were measured. Both right and left limb movements were recorded. Data from the goniometer were acquired at a rate of 100 samples per second and transcribed to permanent digital storage for further analysis. The ankle and knee angles were computed from the three recorded angles.

Initially an attempt was made to record the time of heel strike (HS) and toe off (TO) using small pressure switches taped to the sole of the foot. This was found to give unreliable measurements and was abandoned in favour of manual selection of swing phase, using the ankle and knee

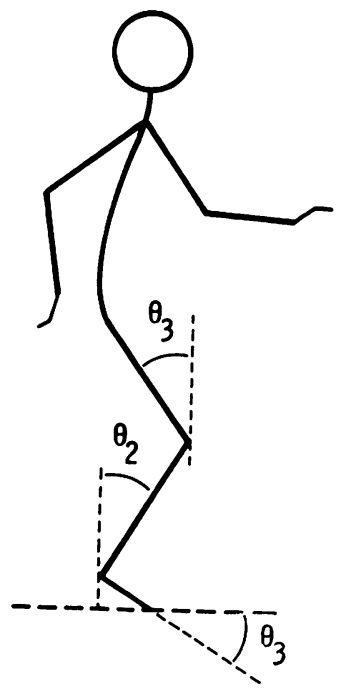

Fig 1 Angles measured at the ankle and knee during walking.

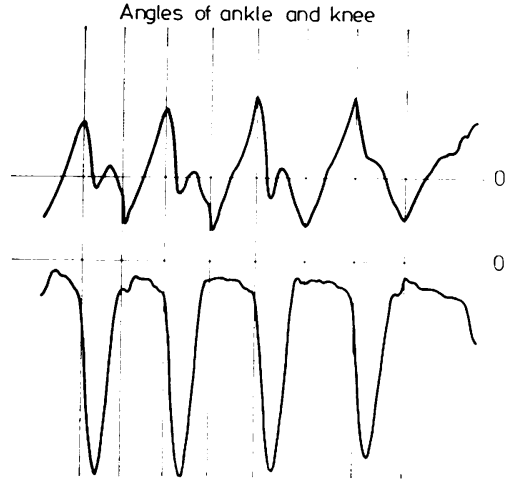

Fig 2 Graph of ankle and knee angles against time for 4 complete cycles.

angle plot (fig 2). Whilst it was appreciated that this manual method could be prone to error, it was found in practice that repeatability of swing phase time definition was superior to using footswitch events. Following definition of swing phase location, the first twelve such artefact-free events were selected from each set of data. Each swing phase was then analysed for the fifteen measures illustrated in fig 3 . The means and standard errors for each measure and for both limbs were computed for each visit of the subject. The standard errors were found to be small relative to the variability between subjects or between visits. Thus the final analysis of the data used a two-way analysis of variance for each measure based upon the mean values determined for each visit and each limb.

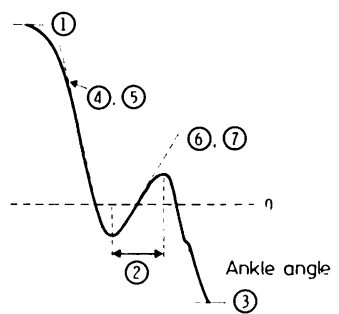

1 Ankle TO angie

2 Dorsitlexion t:m.

3 Ankle angle of $\mathrm{H}_{3}$

4 Mean dorsiflexion rate

5 Peak dorsiflexion rate

6 Mean plantar flexion rate

7 Peak plantar flexion rute

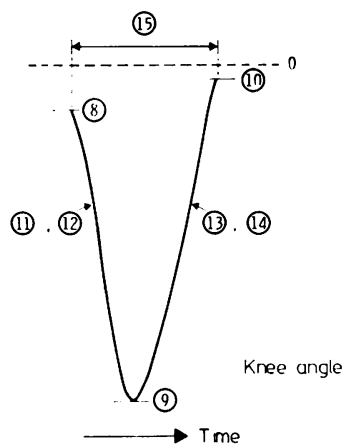

8 Knee angle at TO

9 Peak knee angle

11) Knee angle at $\mathrm{HS}$

11 Mean flexion rate

12 Peak flexion rate

13 Mean extension rate

14 Peak extension rate

15 Time of swing phase

Fig 3 Details of indices measured from each of the swing phases. 
Table 2 Scores for clinical parameters assessed

\begin{tabular}{|c|c|c|c|c|}
\hline & $\begin{array}{l}\text { Before } \\
\text { treatment }\end{array}$ & Placebo & Baclofen & DS103-282 \\
\hline a. General mobility & 12 & 12 & 12 & 12 \\
\hline b. Urinary frequency & 6 & 5 & 8 & 5 \\
\hline $\begin{array}{l}\text { c. Spasms } \\
\text { d. Power }\end{array}$ & 7 & 4 & 4 & 6 \\
\hline Hip flexion Right & 37 & 38 & 38 & 37 \\
\hline $\begin{aligned} \text { Left } \\
\text { Knee extension }\end{aligned}$ & 38 & 39 & 38 & 38 \\
\hline Right & 43 & 45 & 44 & 44 \\
\hline Left & 43 & 45 & 45 & 45 \\
\hline
\end{tabular}

All figures obtained by summating the scores for each individual.

Table 3 Change in leg stiffness as assessed by the patient

\begin{tabular}{llll}
\hline & Placebo & Baclofen & DS103-282 \\
\hline Improved & 5 & 5 & 3 \\
Unchanged & 3 & 3 & 5 \\
Worsened & 2 & 2 & 2 \\
\hline
\end{tabular}

\section{Results}

CLINICAL ASSESSMENT

As can be seen from Table 2 general mobility did not alter when any form of treatment was used, nor was there any consistent change in power in the lower limbs, as assessed by flexion at the hips and extension at the knees. Spasms in the lower limbs were reported as being less severe when baclofen and placebo were taken. During treatment with baclofen urinary frequency was reported as more of a problem than when the patients were taking no treatment, placebo or DS103-282.

Stiffness in the legs, as assessed by the patients themselves, was not consistently improved by any form of treatment as shown in table 3. Whilst taking baclofen or placebo five patients reported an improvement in lower limb stiffness, three felt that their leg stiffness was unchanged and two patients thought it was worse; whilst taking DS103-282 three patients felt there had been an improvement, five thought there was no change and two that there had been a worsening of leg stiffness. However the

Table 4 Extent to which leg stiffness interfered with walking as assessed by the patient

\begin{tabular}{llll}
\hline & Placebo & Baclofen & DS103-282 \\
\hline Right leg & 20 & 17 & 15 \\
Left leg & 13 & 12 & 11 \\
\hline
\end{tabular}

The lower the score the less walking was impaired by stiffness.

Table 5 Range of movements (degrees) about the ankle and knee. All values are mean.

\begin{tabular}{|c|c|c|c|c|c|c|c|c|}
\hline & \multicolumn{4}{|l|}{ Left leg } & \multicolumn{4}{|l|}{ Right leg } \\
\hline & $\begin{array}{l}\text { Before } \\
\text { treatment }\end{array}$ & Placebo & Baclofen & DS103-282 & $\begin{array}{l}\text { Before } \\
\text { treatment }\end{array}$ & Placebo & Baclofen & DS103-282 \\
\hline $\begin{array}{l}\text { Ankle angle at toe off } \\
\text { Ankle angle at heel strike } \\
\text { Knee angle at toe off } \\
\text { Knee peak angle } \\
\text { Knee angle at heel strike }\end{array}$ & $\begin{array}{r}6.6 \\
-\quad 0.9 \\
-\quad 5 \cdot 7 \\
-22.6 \\
-\quad 7 \cdot 1\end{array}$ & $\begin{array}{c}8 \cdot 5 \\
0 \cdot 0 \\
-\quad 5 \cdot 6 \\
-23 \cdot 2 \dagger \\
-\quad 6 \cdot 6\end{array}$ & $\begin{array}{l}\quad 7 \cdot 7 \\
-\quad 0 \cdot 3 \\
-\quad 5 \cdot 7 \\
-23 \cdot 6+ \\
-\quad 5 \cdot 9\end{array}$ & $\begin{array}{l}7 \cdot 3 \\
-\quad 1 \cdot 1 \\
-5 \cdot 6 \\
-23 \cdot 3 \dagger \\
-\quad 5 \cdot 8\end{array}$ & $\begin{array}{r}7 \cdot 5 \\
-\quad 0 \cdot 3 \\
-\quad 6 \cdot 3 \\
-25 \cdot 1 \\
-\quad 5 \cdot 6\end{array}$ & $\begin{array}{r}7 \cdot 0 \\
-\quad 0.3 \\
-\quad 6 \cdot 5 \\
-24 \cdot 8 \\
-\quad 6 \cdot 7\end{array}$ & $\begin{array}{l}\quad 8 \cdot 9 \\
-\quad 0 \cdot 3 \dagger \\
-\quad 5 \cdot 9 * \\
-25 \cdot 4 \\
-\quad 5 \cdot 8\end{array}$ & $\begin{array}{l}6.9 \\
-\quad 1 \cdot 4 \dagger \\
-5 \cdot 0^{*} \\
-23 \cdot 8 \\
-\quad 5 \cdot 5\end{array}$ \\
\hline \multicolumn{9}{|l|}{$\begin{array}{l}\text { - indicates flexion } \\
* \mathrm{p}<0.01 \\
+\mathrm{p}<0.05\end{array}$} \\
\hline & \multicolumn{4}{|l|}{ Left leg } & \multicolumn{4}{|l|}{ Right leg } \\
\hline & $\begin{array}{l}\text { Before } \\
\text { treatment }\end{array}$ & Placebo & Baclofen & DS103-282 & $\begin{array}{l}\text { Before } \\
\text { treatment }\end{array}$ & Placebo & Bacloben & DS103-282 \\
\hline \multicolumn{9}{|l|}{ Ankle dorsiflexion } \\
\hline Mean & $24 \cdot 9$ & $25 \cdot 6$ & $24 \cdot 6$ & $23 \cdot 4$ & $23 \cdot 5$ & $25 \cdot 1$ & $23 \cdot 9$ & $23 \cdot 4$ \\
\hline Peak & $48 \cdot 4$ & $49 \cdot 2$ & $50 \cdot 6$ & $45 \cdot 3$ & $48 \cdot 6$ & $46 \cdot 3$ & $45 \cdot 6$ & $43 \cdot 2$ \\
\hline \multicolumn{9}{|l|}{ Ankle plantar flexion } \\
\hline $\begin{array}{l}\text { Mean } \\
\text { Peak }\end{array}$ & $\begin{array}{l}-38.8 \\
-95.4\end{array}$ & $\begin{array}{l}-37 \cdot 7 \\
-88 \cdot 0\end{array}$ & $\begin{array}{l}-40 \cdot 3 \\
-101 \cdot 0\end{array}$ & $\begin{array}{l}-35 \cdot 4 \\
-\quad 87 \cdot 4\end{array}$ & $\begin{array}{l}-35 \cdot 3 \\
-\quad 94 \cdot 8\end{array}$ & $\begin{array}{l}-33.9 \\
-80.6\end{array}$ & $\begin{array}{l}-37 \cdot 9 \\
-\quad 97 \cdot 2\end{array}$ & $\begin{array}{l}-35 \cdot 4 \\
-85 \cdot 2\end{array}$ \\
\hline \multicolumn{9}{|l|}{ Knee Flexion } \\
\hline Mean & $-61 \cdot 1$ & -56.9 & -60.4 & $-59 \cdot 1$ & $-63 \cdot 5$ & $-60 \cdot 5$ & -63.0 & $-60 \cdot 7$ \\
\hline $\begin{array}{l}\text { Peak } \\
\text { Knee extension }\end{array}$ & $-116 \cdot 3$ & $-117 \cdot 3$ & $-117 \cdot 7$ & $-114 \cdot 9$ & $-123 \cdot 3$ & $-119 \cdot 6$ & $-126 \cdot 6$ & $-121 \cdot 2$ \\
\hline Mean & $48 \cdot 0$ & $53 \cdot 5$ & $56 \cdot 7$ & $50 \cdot 1$ & $54 \cdot 5$ & $53 \cdot 5$ & $57 \cdot 4$ & $54 \cdot 5$ \\
\hline Peak & $98 \cdot 1$ & $106 \cdot 4$ & 114.9 & $107 \cdot 7$ & $116 \cdot 2$ & $100 \cdot 2$ & $112 \cdot 1$ & $105 \cdot 9$ \\
\hline Duration of swing phase & $0 \cdot 7$ & $0 \cdot 7$ & 0.6 & 0.7 & 0.7 & 0.7 & 0.7 & 0.7 \\
\hline
\end{tabular}

- indicates flexion at the knee joint and plantar flexion at the ankle joint. 
patients felt that leg stiffness was interfering with walking least when DS103-282 was being taken and less when baclofen was being prescribed than when a placebo was given (table 4).

GAIT ANALYSIS

Mean values for all the parameters measured are shown in tables 5 and 6 . There were few parameters which altered when the patient was receiving placebo, baclofen or DS103-282. For the right leg the ankle angle at heel strike was more plantar flexed $(\mathrm{p}<0.05)$ when the patients were taking DS103-282 and more dorsiflexed $(p<0.05)$ when taking baclofen. In addition the knee angle at toe off was more extended when the patients were taking DS103-282 or baclofen $(<0.01)$ than when taking no treatment or placebo. For the left leg the knee peak angle was more flexed $(p<0.05)$ when the patients were taking a placebo, DS103-282 or baclofen than when no treatment was being given.

\section{Discussion}

In the assessment of the value of drug treatment for spasticity an objective measurement should provide greater accuracy than either the patients subjective experience or clinical examination. The objective method of assessment used should measure parameters which directly relate to the symptoms that it is hoped to improve.

In ambulant patients drugs to relieve spasticity are usually given to improve gait yet most objective methods used to evaluate such drugs do not measure parameters of gait but rather determine spasticity in muscles which are passively stretched. ${ }^{3}$ Since there is evidence that the response of spastic muscles to lengthening differs during passive and voluntary movement ${ }^{4}$ alterations in spasticity measured by such techniques may not accurately reflect changes which occur during walking. During a complex activity such as walking there may be a further modification of reflex activity and the response to drugs may therefore be different from that obtained in experimental situations involving only passive flexion and extension. Objective measurement of parameters of the spastic gait should therefore permit a better assessment of the value of an antispasticity drug in ambulant patients.

Measurement of parameters of gait in spasticity is based upon the fact that spasticity reduces the range and velocity of movement of limbs. Relief of spasticity, therefore, in the absence of excessive weakness, should result in movement which is greater in range and velocity. 3 Cine films and interrupted light photography have previously been used to assess gait in spasticity ${ }^{3}$ whilst some studies have measured the electromyographic activity in muscles during walking. ${ }^{5}$ We, however, chose the technique of polarised light goniometry since it permits determination of the angular orientation of limb segments with respect to the vertical or horizontal with an accuracy better than 0.5 of a degree ${ }^{6}$ and as such provides an accurate method for the determination of the range and velocity of limb segments during walking.

The results of this investigation demonstrate a wide variation in symptoms and performance that is largely independent of any treatment. This variability conceals any possible benefit from a drug such as baclofen when double blind assessment was carried out. Thus patients subjective assessment of "stiffness" in the legs was not improved by baclofen or DS103-282 when compared with placebo although the degree to which leg stiffness affected gait was thought to be less when these drugs were being taken. The parameters of gait measured by polarised light goniometry and selected to demonstrate "improvement" showed only marginal alterations as a result of drug treatment. Thus the ankle at the end of the swing phase of walking was more dorsiflexed on baclofen and more plantarflexed on DS103-282 than on placebo and whilst taking both DS103-282 and baclofen the knee angle at toe off was more extended at the start of the swing phase of walking.

It is of interest that the observation that DS103282 had a more pronounced effect on plantarflexion is compatible with the findings of Hassan and McLellan ${ }^{7}$ that the extensor muscles are more effectively suppressed than the flexors. The fact that there was an increase in the range of movement at the ankle and knee without an increase in angular velocity might be explained by an increase in the speed of progression over the walkway with treatment. We have no evidence, however, that this did increase and in particular there was no difference in the duration of the swing phase between the series of observations.

Subjective improvement in response to spasmolytic agents is variable and the failure of patients to improve with treatment may reflect the fact that they are poor responders to agents of this type. Our patients were an unselected group, the majority of whom had not previously received antispasticity drugs and there is no reason to suspect that they should be resistant to such treatment. However, in this study both DS103-282 and baclofen produced only minimal subjective and objective changes in gait and DS103-282 compared unfavourably with baclofen. Nonetheless we believe that gait analysis provides a more accurate method of assessing abnormal gait than either the patient's subjective experience or clinical methods of evaluation. 
We are grateful to Sandoz Products for a supply of DS103-282, to Professor Waugh for permission to use equipment belonging to his department and to Mrs B George for help with the preparation of the manuscript.

\section{References}

${ }^{1}$ Gowers WR. A Manual of Diseases of the Nervous System. Hafner Publishing Co, Darien, Conn. 1893. Republ. 1970.

2 Duncan GW, Shahani BT, Young RR. An evaluation of baclofen treatment for certain symptoms in patients with spinal cord lesions. Neurology (Minneap) 1976; 24:441-6.
${ }^{3}$ Pedersen E. Clinical assessment and pharmacologic therapy of spasticity. Arch Phys Med Rehab 1974;55: 344-54.

${ }^{4}$ McLellan DL. Co-contraction and stretch reflexes in spasticity during treatment with baclofen. $J$ Neurol Neurosurg Psychiatry 1977;40:30-8.

${ }^{5}$ Hirschberg GG, Nathanson M. Electromyographic recording of muscular activity in normal and spastic gaits. Arch Phys Med 1952;33:217-25.

${ }^{6}$ Mitchelson D. Spasticity and cerebral pathology. In: Jukes AM, ed. Baclofen. Northampton: Cambridge Medical Publications, 1978:95-102.

${ }^{7}$ Hassan N, McLellan DL. Double-blind comparison of single doses of DS103-282, baclofen and placebo for suppression of spasticity. $J$ Neurol Neurosurg Psychiatry 1980;43:1132-6. 